\title{
Ayahuasca e Redução do Uso Abusivo de Psicoativos: Eficácia Terapêutica?
}

\author{
Rafael Guimarães dos Santos ${ }^{1}$ \\ Universidade de Brasília \\ Célia Carvalho de Moraes \\ Instituto de Gestalt-Terapia de Brasília \\ Adriano Holanda \\ Universidade de Brasília
}

\begin{abstract}
RESUMO - Trata-se de uma avaliação do possível papel do uso da ayahuasca, em contexto religioso, como auxiliar na redução do consumo abusivo de psicoativos, a partir de uma pesquisa de estudo de caso. Foi realizada uma entrevista aberta com uma usuária regular de cocaína, nicotina e álcool que abandonou este comportamento após entrar em contato com a ayahuasca num contexto ritualizado. $\mathrm{O}$ caso foi analisado à luz da comparação deste com a literatura existente sobre o assunto. Foi traçada uma relação entre o início do uso da ayahuasca e o abandono do uso de cocaína, nicotina e álcool pela entrevistada, a partir da avaliação das representações simbólicas e das descrições de suas primeiras experiências com a bebida.
\end{abstract}

Palavras-chave: ayahuasca; alucinógenos; psicoativos.

\section{Ayahuasca and Reduction of the Abusive Use of Psychoactives: Therapeutic Efficacy?}

\begin{abstract}
This paper evaluates the possible role of the use of ayahuasca, in a religious context, as an auxiliary in the reduction of the abusive consume of psychoactives, using a case report research. An open interview with a regular consumer of cocaine, nicotine and alcohol, which abandoned this behavior after the encounter with the ritualized use of ayahuasca, was made. The case was analyzed comparing it with the literature on the subject. From the evaluation of the symbolic representations and the descriptions of her first experiences with the brew, a relation was constructed between the moment the interviewee began to use ayahuasca and the moment that she abandoned the use of cocaine, nicotine and alcohol.
\end{abstract}

Key words: ayahuasca; hallucinogens; psychoactives.

A palavra ayahuasca tem sua origem na língua Quéchua, língua falada nos altiplanos andinos (Dobkin de Rios, 1972), e significa, dentre outras, "corda dos mortos", em referência às várias espécies de cipó utilizadas como base da preparação de um psicoativo utilizado por pelo menos 72 grupos indígenas diferentes, espalhados pelo Brasil, Colômbia, Peru, Venezuela, Bolívia e Equador (Luna, 1986). O termo ayahuasca refere-se a diferentes elementos: 1) a força espiritual que estaria presente na substância e 2) a própria substância, que é feita a partir de diferentes espécies do cipó Banisteriopsis (Malpighiaceae) adicionadas com outras plantas (Groisman, 2000) ${ }^{2}$. Pode-se dizer que o termo aplica-se também à substância preparada somente com espécies do cipó, prática esta encontrada, por exemplo, entre os índios Maku, na região fronteiriça entre Brasil e Colômbia (Davis, 1997).

Desde meados do século XIX, com a expansão do Ciclo

1 Endereço: Calle Rosselló 407bis, ent 02, Barcelona, Espanha, 08025. E-mail: banisteria@ gmail.com

2 Principais plantas empregadas como misturas à ayahuasca (Ott, 1994): Achornea castaneifolia, Brunfelsia grandiflora, Mansoa allicea, Illex guayusa, Paullinia yoco, Erythoxylum coca var. ipadú, Nicotiana sp., Brugmansia sp., Brunfelsia sp., Psychotria viridis, Diplopteris cabrerana etc. da Borracha, a ayahuasca vem sendo utilizada por populações não indígenas, como seringueiros, pescadores e agricultores das áreas rurais dos estados brasileiros do Acre e de Rondônia, por exemplo (Araújo, M., 2004). Por volta da segunda década do século XX, no interior de Rio BrancoAC, foi criada por Raimundo Irineu Serra a religião do Santo Daime, culto que consagra a ayahuasca (neste contexto, batizada de Daime) em rituais religiosos com influências do catolicismo popular, do espiritismo kardecista, dos cultos afro e do xamanismo (Couto, 1989; Goulart, 1996; Labate \& Araújo, 2004; MacRae, 1992).

Na década de 1940 foi fundada por Daniel Pereira de Mattos, também em Rio Branco-AC, a Barquinha, religião ayahuasqueira também formada com elementos indígenas, cristãos e afro-brasileiros, com uma maior influência da Umbanda (Araújo, W., 2004; Frenopoulo, 2004; Labate, 2004, Santos, 2004). E em 1961, foi fundada por José Gabriel da Costa, em Porto Velho-RO, a União do Vegetal (UDV), a maior e mais institucionalmente organizada das religiões ayahuasqueiras, cujos ensinamentos são baseados em uma doutrina cristã-reencarnacionista permeada por elementos do espiritismo kardecista e de outras manifestações religiosas urbanas. Além disso, possui um caráter mais sóbrio e menos festivo que as outras organizações (Santo Daime e Barquinha), não praticando danças ou cantos com instrumentos (Brissac, 1999, 2004).

Em recente publicação, Labate (2004) estudou os usos ritualizados da ayahuasca em contextos urbanos, usos estes 
marcados por uma influência de orientalismos, vocabulários provenientes do universo New Age e da Psicologia. Os usos religioso-institucionais da ayahuasca se encontram hoje em vários países do mundo, como Espanha, França, Holanda, Estados Unidos e Japão (Lima, 2004).

\section{Ayahuasca, xamanismo e o uso problemático de psicoativos}

O que caracteriza o uso problemático ou abusivo de certas substâncias não é, necessariamente, a quantidade e a freqüência de uso destes psicoativos, embora estes fatores possam fazer parte do comportamento descrito. Mais do que quantidade de substâncias e frequiência de uso destas, que poderiam atuar num nível primário (físico-biológico) do indivíduo, são as desarmonias na vida sociocultural, familiar e psicosocial deste indivíduo (p. ex., estigmatização no emprego e na vida social mais ampla, isolamento social pela comunidade, maus-tratos por parte da polícia), ou seja, num nível secundário, que seriam as principais características deste uso problemático de psicoativos.

Existem vários relatos na literatura sobre os possíveis efeitos benéficos do uso ritual e/ou supervisionado de substâncias alucinógenas como uma alternativa às terapias contemporâneas para o auxílio na dependência ou no uso problemático de certos psicoativos, sobretudo o álcool (Blewett \& Chwelos, 1959/2005; Carneiro, 2005; Grob, 2002; Grof, 2001).

Logo após a descoberta dos efeitos do LSD-25 por Albert Hofmann em 1943, várias substâncias desta classe foram aplicadas e testadas no contexto psicoterapêutico, médico, espiritual e em práticas "psicoespirituais", ou seja, práticas que, em condições favoráveis de supervisão e preparação, buscam a reestruturação do indivíduo por meio de um estado de consciência cósmica que seria semelhante aos êxtases religiosos espontâneos conhecidos como unio mystica, samadhi ou satori, que são experienciados como uma iluminação por uma realidade transcendente em qual a Criação e o Ego são Um (Schultes \& Hofmann, 1992).

Como exemplo destas práticas pode-se citar a a) terapia psicodélica, na qual, após uma intensa preparação, é administrada uma única dose do psicoativo, dose esta bastante alta, visando desencadear uma experiência místico-espiritual no indivíduo e, a partir daí, elaborar as mudanças cognitivocomportamentais necessárias; e b) a terapia psicolítica, na qual pequenas doses são administradas ao longo do tempo, geralmente semanalmente ou mensalmente, intercaladas por psicoterapias baseadas em grande parte no modelo psicanalítico, com o objetivo de facilitar o processo de transferência entre o paciente e o terapeuta e, além disso, facilitar o acesso a memórias reprimidas da infância (Adaime, no prelo; Grob, 2002; Grof, 2001; Schultes \& Hofmann, 1992).

Esta opção de se utilizar certos psicoativos para auxiliar o tratamento do uso abusivo de outros psicoativos também ocorre em grupos indígenas extremamente afetados pelo álcool. $\mathrm{O}$ fato de o álcool ser muitas vezes uma substância exógena e descontextualizada nestes grupos humanos, pode ser um dos motivos de seu abuso por parte desta população (Mabit, 2002). Como exemplos do uso tradicional de psicoativos no tratamento do alcoolismo pode-se citar a) o uso ritual de cactos contendo mescalina por parte dos curandeiros da costa peruana, uma prática com uma alta taxa de sucesso (por volta de $60 \%$, após cinco anos) e b) a recuperação de práticas ancestrais, incluindo o uso ritual do peiote e do tabaco, por grupos indígenas norte-americanos (Mabit, 2002).

No final da década de 60 do século XX, devido às informações alarmistas provenientes da mídia e à expansão do uso de alucinógenos dos centros de pesquisa das faculdades para as ruas, a pesquisa envolvendo seres humanos e estas substâncias foram proibidas, dificultando o aprofundamento dos potenciais neuroquímicos e psicoterapêuticos destas substâncias peculiares (Carneiro, 2005; Grob, 2002; Grof, 2001). No entanto, o uso religioso de certos vegetais como o peiote nos EUA e México, a iboga na África, e a ayahuasca no Brasil e na Amazônia Ocidental, continuou sendo praticado com uma certa liberdade e autonomia (Fericgla, 1998; Furst, 1994; Labate, 2003).

Nestes contextos, as plantas são carregadas de um simbolismo altamente complexo, no qual fazem parte de seu consumo os aspectos: a) biológicos - a planta em si, suas substâncias e o organismo do indivíduo; b) psicológicos - o indivíduo, suas expectativas, motivações e preparações para o consumo do psicoativo; c) socioculturais - o indivíduo, sua comunidade e suas regras sociais; e d) ambientais - local do uso da substância, música, danças, plantas aromáticas, decoração etc (Grob, 2002; Grof, 2001; Leary, Metzner \& Alpert, 1964/1995). Tanto a mescalina (do peiote) como a ibogaína (da iboga) vêm sendo estudadas como possíveis alternativas para a dependência e o uso problemático de psicoativos (Grof, 2001; Labate, 2003).

Recentemente, um estudo realizado com 15 membros da União do Vegetal que consagravam a ayahuasca ritualmente por pelo menos 10 anos demonstrou, entre outras coisas, que de acordo com os critérios da CID-10 e DSM-III-R, cinco dos examinandos tinham antecedentes de desordens formais por abuso de álcool, dois de depressão maior e três de ansiedade fóbica; 11 examinandos tinham uma história de uso moderado a grave de álcool anterior à sua entrada na UDV, com cinco deles referindo episódios associados com comportamento violento (dois deles tinham sido presos por causa de sua violência) (Grob \& cols., 2004).

Além destes dados, o estudo de Grob e cols. (2004) evidenciou que quatro indivíduos também relataram envolvimento anterior com abuso de outros psicoativos, incluindo cocaína e anfetamina, e que oito dos 11 examinandos com histórias anteriores de álcool e abuso de outros psicoativos eram dependentes de nicotina na época do seu primeiro encontro com a UDV. Muitos dos examinandos do estudo de Grob e cols. referiram uma variedade de comportamentos disfuncionais anteriores à sua entrada na UDV. Autodescrições incluíram "impulsivo, sem respeito, raivoso, agressivo, opositor, rebelde, irresponsável, alienado, fracassado".

Entretanto, avaliações de diagnóstico psiquiátrico revelaram que apesar de uma porcentagem apreciável de usuários de longo tempo da ayahuasca terem tido desordens relativas ao álcool, depressivas ou de ansiedade anteriores à sua iniciação com o alucinógeno, todas as desordens tinham remitido sem recaídas depois de sua entrada na UDV. Os examinandos referiram que desde sua entrada na UDV suas vidas passaram por mudanças profundas. Além da total descontinuidade do abuso de psicoativos, os sujeitos enfaticamente afirmaram que sua conduta diária e orientação para o mundo à sua volta tinham tido radical reestruturação (Grob \& cols., 2004). 
Baseado no estudo de Grob e cols. (2004), Labigalini (1998) desenvolveu uma pesquisa sobre as vivências subjetivas de quatro indivíduos que apresentavam dependência grave ao álcool, dois deles também dependentes de cocaína, e que remitiram poucos meses após começarem a freqüentar os rituais da UDV. A principal conclusão do trabalho foi a de que os indivíduos entrevistados não trocaram a dependência ao álcool por outra dependência. Além disso, ficou evidenciado que o uso de ayahuasca que esses indivíduos passaram a fazer periodicamente durante os rituais não possuía contornos psicopatológicos de uma compulsão. Esta compulsão também não foi encontrada na relação destes indivíduos com a instituição religiosa, por meio de seus valores e práticas rituais, e com o grupo (Labigalini, 1998).

Baseando-se na análise das entrevistas e nas observações participantes neste estudo, Labigalini apontou os seguintes fatores como variáveis importantes na melhora dos sujeitos: a) as características do estado de consciência vivenciados nas experiências com a ayahuasca, b) a inserção social em um novo grupo e c) a estruturação e regulação dos rituais por meio de suas sanções sociais.

Ainda neste contexto, vale citar a existência do Centro Takiwasi, em Tarapoto, Peru, fundado em 1992 (Mabit, 2004). Neste centro, Mabit e colaboradores - curandeiros locais, médicos, psicólogos e terapeutas - exploram os potenciais curativos do racionalismo ocidental juntamente com as práticas espirituais do xamanismo e das terapias tradicionais amazônicas, utilizando plantas eméticas, dietas, isolamento na floresta, vida comunitária, psicoterapia e a ayahuasca, desenvolvendo métodos alternativos para lidar com o uso problemático de psicoativos, principalmente a pasta base de cocaína, cuja área é uma das principais consumidoras do mundo (Mabit, 1996a, 1996b, 2002). Segundo Mabit (2002, p. 28):

\begin{abstract}
Após 15 anos de observação de mais de oito mil casos de ingestão da Ayahuasca sob condições específicas de preparação, prescrição e acompanhamento terapêutico, nós podemos afirmar que a ingestão destas preparações possui uma ampla variedade de indicações, com uma total ausência de dependência. A expansão do espectro perceptual, que simultaneamente envolve o corpo, as sensações e os pensamentos, permite a des-focalização da percepção ordinária da realidade, proporcionando ao sujeito a possibilidade de confrontar seus problemas habituais por conta própria e sob uma nova perspectiva. A intensa aceleração dos processos cognitivos que acompanha esta experiência pode permitir ao sujeito a capacidade de conceber soluções originais que se enquadram à sua personalidade e situação únicas.
\end{abstract}

A partir destas referências e modelos teóricos pretendemos elaborar e investigar, por meio da análise fenomenológica da entrevista e de observações participantes em rituais de consagração da ayahuasca, o caso de uma jovem que abandonou o uso problemático de álcool, cocaína e nicotina após conhecer o uso ritualizado da ayahuasca. Esta jovem apresentou-se como uma voluntária para a realização de uma pesquisa sobre os aspectos legais, históricos, doutrinários e religiosos do uso da ayahuasca, trabalho este que partiu dos estudos do grupo Arché - Programa de Pesquisas em Psicologia e Fenomenologia da Religião e da Espiritualidade
-, que se encontra atualmente vinculado ao Laboratório de Psicopatologia e Psicanálise, do Departamento de Psicologia Clínica, no Instituto de Psicologia da Universidade de Brasília (UnB).

\section{Método}

Trata-se de um estudo de caso associado a uma revisão bibliográfica sobre o consumo ritualizado da ayahuasca por pessoas que faziam um uso abusivo ou problemático de outras substâncias - cocaína e pasta base de cocaína, álcool, nicotina, anfetaminas etc - e que posteriormente abandonaram ou controlaram este comportamento. Foram utilizadas técnicas da antropologia, como a observação participante, realizada em diversos grupos ayahuasqueiros nos arredores de Brasília, e referenciais teóricos do grupo Arché, como o texto de Amatuzzi (1998).

No grupo Arché, tivemos contato com Maria (nome fictício), jovem desinibida e espontânea com 20 anos na época e que se apresentou como estudante universitária com pendores artísticos, segundo ela mesma, membro de um grupo que utiliza a ayahuasca em suas cerimônias religiosas e como voluntária para nos auxiliar na pesquisa mais ampla sobre a ayahuasca. Maria começou nos ajudando no levantamento de documentos sobre as principais religiões ayahuasqueiras brasileiras (Santo Daime, Barquinha e União do Vegetal) e nas semanas subseqüentes permitiu que fizéssemos uma entrevista aberta sobre sua experiência pessoal com a ayahuasca. Esta entrevista ocorreu na casa de um dos autores do presente artigo, em um ambiente de tranquiilidade e conforto. A entrevista, aberta, foi norteada por perguntas abertas, tais como: "O que é a ayahuasca para você?", "Como foi a sua primeira experiência com a ayahuasca?", "Porque ou com que finalidade você utiliza a ayahuasca?". Esta entrevista foi gravada, transcrita e posteriormente analisada.

Na conversa com Maria, chamou a atenção o fato de que ela fazia um uso abusivo de álcool, cocaína e nicotina e que este comportamento se remitiu pouco tempo após o início do consumo cerimonial da ayahuasca. Não só o uso problemático de alguns psicoativos foi abandonado, mas Maria passou por uma transformação radical em seus valores e atitudes perante o mundo. Este trajeto foi descrito com detalhes em sua entrevista e enfocou-se a relação entre o abandono do uso de álcool, cocaína e nicotina e o início do uso religioso da ayahuasca.

O rico e complexo material proveniente deste recorte foi re-analisado e comparado com a literatura sobre o assunto, buscando avaliar os elementos significativos da experiência de Maria nos estados alterados de consciência proporcionados pelo uso da ayahuasca em contexto ritualizado.

\section{Resultados e Discussão}

Apenas trechos de maior importância serão comentados. As palavras textuais da entrevistada foram assinaladas em itálico.

Maria apresentou-se como uma jovem de vida turbulenta, vida esta caracterizada por uma busca de algo e por 
um envolvimento com certos psicoativos - álcool, cocaína e nicotina - e com pessoas que não eram muito legais. Ela havia consumido cocaína por dois anos consecutivos quase todo dia, segundo ela, além do álcool e da nicotina. Não gostava de religião. Antes de conhecer a ayahuasca Maria já tinha uma intenção, uma iniciativa pessoal de parar de usar os outros psicoativos, substâncias que ela caracterizou como estimulantes, da vida noturna.

Porque eu fiquei um ano sem ver Sol. Só saia seis horas de casa e voltava sete horas da manhã. Dormia o dia inteiro, saía... Não fazia nada, não estudava... Era maluca.

Foi quando Maria conheceu pessoas que não faziam parte de seu contexto que sua vida começou a mudar. Durante uma crise de abstinência Maria viu a oportunidade de conhecer a ayahuasca que, segundo ela, a salvou:

Aí eu comecei uma crise de abstinência e no dia que eu conversei com o João (nome fictício), que foi a pessoa que me levou para conhecer o vegetal (nome da ayahuasca neste contexto), falei para ele "João, sabe onde vende cocaína?", "Sei”, "Vamos sair comigo na sexta?”, "Não, eu tenho compromisso”, "Para onde você vai?", "Vou beber um chá", "Me leva?". Aí ele me levou. Aí eu me salvei.

Em seu primeiro contato com a ayahuasca - caracterizado pela entrevistada como sendo a experiência mais forte e poderosa - Maria relatou vivências de caráter místico-religioso, alteração de percepções e de emoções, susto, medo de morrer, reações somáticas intensas como vômito, choro e tosse além de ab-reações e catarses. Estas experiências, realizadas em um local onde ocorrem periodicamente cerimônias com a ayahuasca, estavam culturalmente contextualizadas e sancionadas, permeadas por conceitos próprios e, de certo modo, eram inclusive estimuladas.

Segundo Mabit (2002, pp. 26-27), "a indução ritualizada de modificações da consciência, com ou sem substâncias, estabelece uma estrutura simbólica universal dentro da qual estas experiências adquirem significado, permitindo que o indivíduo se inscreva dentro de um modelo de integração cultural".

O ambiente físico e o contexto simbólico-ritual onde se realizou a cerimônia, o setting, era propício para este tipo de experiência. Segundo Strassman (1984), um ambiente controlado e supervisionado, como geralmente ocorre nas religiões ayahuasqueiras, tem uma maior possibilidade de otimizar as experiências com substâncias alucinógenas, como a ayahuasca, diminuindo as chances da ocorrência de reações adversas. Neste caso, o ambiente exerce papel primordial na experiência como um todo.

No contexto em questão, as reações somáticas foram explicadas e encaradas por Maria como sendo um processo de limpeza, no qual, juntamente com as visões e demais experiências sensoriais e cognitivas proporcionadas pela ayahuasca, toda a experiência pode ser reconstruída e contextualizada, permitindo a reavaliação de comportamentos, valores e atitudes anteriores de Maria.

Comecei a sentir minha pressão baixa. Nesse momento eu fiquei assustada porque eu tinha pressão baixa e achei que podia ter um problema. Percebi que quanto mais eu lutava contra aquela sensação pior ela ficava, uma sensação bem forte. Relaxei, deitei, e quando eu deitei comecei a ver cobras, umas coisas bem esquisitas mesmo. Vomitei muito nesse momento, e quando vomitava eu não vomitava coisa do estômago, eu vomitava álcool, eu bebia muito... Eu vomitava e sentia cheiro de álcool. Cheirei muita cocaína... Tive nesse momento de limpeza um dos momentos mais fortes da minha vida, mais incriveis, porque foi uma potência de informações do meu ser e uma limpeza... Senti minha garganta arranhar, minha cabeça doía e adormeceu minha boca e eu não forcei nada pra sair do meu nariz, simplesmente saiu uma placa branca, uma placa assim no chão e eu “Caramba! Isso aqui é cocaína”. Peguei e disse "Me limpou!". Depois disso eu comecei a chorar muito, mas eu chorava de alegria, eu estava me sentindo tão bem naquele momento, tão bem tão bem tão bem e ao mesmo tempo eu estava triste porque eu sabia que a minha caminhada ia ser longa, que eu tinha muita coisa para resolver. Aí eu pensei na minha família, no meu pai na minha mãe, quanto tempo que eu não tinha uma relação legal com eles sabe? Regressão, lembrei da minha infância... Uma pessoa na fogueira falou "É assim mesmo. A gente limpa, faz. a limpeza, têm essa relação mesmo...”. Estava uma noite linda, uma lua cheia maravilhosa, eu nunca tinha percebido o tanto que a natureza é linda... Naquele momento eu percebi que é de lá que eu vim. Senti-me viva naquele momento. Eu acordei, como se eu tivesse acordado para vida, sabe?

Pode-se perceber na fala uma enorme carga emocional depositada em três momentos principais: religação com os valores familiares, integração com a Natureza e, principalmente, durante os processos de limpeza, processos estes comuns nos meios ayahuasqueiros (p. ex., Couto, 1989). Nesta limpeza, o que mais chama a atenção são as percepções do cheiro de álcool e da visão da placa de cocaína que teria saído de seu nariz. Sabe-se que a ayahuasca, bem como demais substâncias desta classe, tem a capacidade de desencadear sinestesias e que estas podem ser manipuladas para os mais diversos fins, inclusive com finalidades terapêuticas (Luna, 1986). Ao estudar as práticas dos vegetalistas e dos xamãs sul-americanos, Luna (1986, p. 106) os caracteriza como mestres de sinestesia:

Suas músicas (do xamã, entre os Shipibo-Conibo) podem, por assim dizer, ser ouvidas de maneira visual e os padrões geométricos podem ser vistos acusticamente. Este fenômeno é freqüentemente relatado nos textos das canções xamânicas. Por exemplo, um remédio pode ser chamado de 'minha música pintada', 'minha voz', 'meu pequeno vaso pintado', 'minhas palavras com aqueles desenhos', ои 'meu padrão vibrante.

No caso das alterações sensoriais, emotivas e cognitivas, e independente de se classificar o que ela passou como sendo sinestesia, alucinação, ilusão, imaginação ou se ela realmente sentiu o cheiro de álcool ou se o que ela viu era

3 Curandeiros que habitam o interior do Peru e da Colômbia que adquirem seus conhecimentos sobre o mundo sobrenatural, doenças e saúde diretamente de algumas plantas especiais, como por exemplo, ayahuasca, tabaco, diversas espécies da família Solanaceae etc (Luna, 1986). 
realmente cocaína, o que deve ser levado em consideração é o potencial transformativo que esta experiência tem para o indivíduo. Claro, seria de muito interessante saber se a ayahuasca teria esta capacidade de "limpar", literalmente, o organismo de um ser humano nestes níveis, mas esta é uma pergunta que não poder ser respondida pela presente pesquisa.

Neste processo relatado por Maria, a alta carga emocional e cognitiva presente em suas experiências e falas demonstra um enorme potencial para que uma mudança de seus valores e atitudes possa ocorrer. Tal experiência do transcendente se assemelha às psicoterapias psicodélicas praticadas nos anos 1960 com substâncias como o LSD-25, na qual um dos objetivos buscados e muitas vezes atingidos, era o da mudança radical de valores, filosofia de vida e atitudes perante os outros, o mundo e consigo mesmo (Grof, 2001).

Vale ainda citar a importância e a compreensão do papel da amizade para a análise do processo de Maria. Durante o período turbulento de sua vida, ela disse que estava andando com pessoas não muito legais, mas que ao se afastar destas pessoas, ela pôde conhecer a ayahuasca e outro grupo social. Neste novo contexto Maria descobre amigos mesmo, que a auxiliam:

Só me auxiliam aqui. E a amizade, e as pessoas que eu convivo... nossa, muito, muito, muito bom. São amigos mesmo, porque amigo hoje em dia é difícil né? É difícil, porque agente convive com várias pessoas ao mesmo tempo e acha que um é amigo, outro é amigo. Vou te dizer que desde quando eu comecei a beber o vegetal, eu percebi que daquela galera que eu andava antes, quem são meus amigos daquela galera... Eu tinha assim cerca de uns 40 amigos, que eu achava que eram amigos.

Entretanto, Maria parece atribuir grande responsabilidade por sua "cura" a si mesma, à ayahuasca e a colocar em prática aquilo que aprendeu nos rituais. Mesmo não menosprezando o possível papel do acolhimento em um contexto religioso, da mudança de amizades e da melhora das relações interpessoais como prováveis causas de sua mudança de comportamento, Maria diz que:

Foi o vegetal mesmo. Na verdade não foram as pessoas, foi eu mesma que me encontrei. Não foi o contexto não, isso é conseqüência. Não adianta nada eu ir lá beber o chá, posso beber um litro de vegetal, posso beber todo dia, se eu receber o que é certo e não colocar em prática na minha vida eu vou ficar empacada. (...) É só agente querer mesmo.

No caso do estudo realizado por Grob e cols. (2004) com membros da União do Vegetal, encontramos paralelos entre as experiências relatadas pelos membros da UDV e aquelas descritas por Maria. Todos os examinandos da UDV relataram que suas experiências com o uso ritual da ayahuasca tiveram um profundo impacto no curso de suas vidas. Para muitos deles o ponto crítico foi sua primeira experiência com a bebida, quando relatam como tema comum desta experiência a vivência de se estar num caminho autodestrutivo que os conduziria inevitavelmente à sua própria ruína e mesmo à morte, a menos que embarcassem numa mudança radical de sua conduta pessoal e orientação (Grob
\& cols., 2004).

Maria relata que as experiências com a ayahuasca teriam a capacidade de mostrar a verdade, e que este tipo de vivência seria para nos encontrarmos. Além disso, a bebida psicoativa seria como um amigo, idéia que lembra o conceito de planta professora ou espírito planta, presente entre as religiões ayahuasqueiras e também entre os curandeiros da Amazônia (Luna, 1986; MacRae, 1992):

Porque ele fala mesmo, ele coloca agente lá no acocho, ele dá paulada na gente...

Por meio destas falas, nas quais fica evidente o discurso de autoconhecimento e de encontro com a realidade, e não a fuga desta, podemos encontrar semelhanças entre as experiências e valores atribuídos à ayahuasca por Maria e as vivências dos indivíduos pesquisados por Labigalini (1998, pp. 58-59):

\begin{abstract}
Através das entrevistas foi possível perceber que os indivíduos entrevistados relatavam que no período em que estavam usando álcool e outras drogas sentiam muita ansiedade e apresentavam dificuldades emocionais importantes em suas vidas. No entanto, ao começarem a freqüentar os rituais da UDV e beberem a ayahuasca, referiram que passaram por mudanças profundas a partir de um contato direto com aspectos dificeis de suas personalidades. Neste sentido, a experiência com a ayahuasca parece não reproduzir um aspecto presente na experiência e na busca dos farmacodependentes, onde o uso das diferentes substâncias, como o álcool e a cocaína, acontece motivado por uma vontade de obter prazer e se distanciar da realidade.
\end{abstract}

Levando-se em conta todas estas análises, citações e observações sobre a relação do uso cerimonial da ayahuasca e o abandono do uso problemático de psicoativos, vale citar que, em relação à dependência pelo álcool, estudos realizados com inibidores de recaptação de serotonina com ratos dependentes de álcool demonstraram que havia uma redução importante no consumo de álcool após tratamento com estes agentes (Labigalini, 1998). No caso da ayahuasca, existem relatos de que uma das suas principais substâncias - a $\beta$-carbolina tetrahidroharmina, ou THH, presente no cipó - teria uma fraca capacidade de inibir a recaptação de serotonina (Frecska, White \& Luna, 2004; McKenna, Callaway \& Grob, 1998).

Logo, mesmo comentando de maneira breve e simples este aspecto psicofarmacológico da ayahuasca - pois não é o objetivo deste artigo - valeria a pena explorar de maneira metódica e a longo prazo, o possível papel do chá per se como um agente farmacologicamente eficaz no auxílio do tratamento de dependência ou uso problemático de psicoativos.

\section{Conclusões}

Segundo alguns pesquisadores (Samorini, 2002), o desejo de alterar periodicamente a consciência seria um impulso inato ao ser humano, análogo à fome ou ao impulso sexual. Além disso, encontramos em McKenna, T. (1995) e em Amatuzzi (1998) sugestões de que a consciência religio- 
sa seria biologicamente natural à espécie humana, tendo se desenvolvido por meio do processo de seleção natural, pois teria valor de adaptação e subsistência para o indivíduo, pois estas experiências místico-religiosas seriam potencialmente adaptativas e ligadas à solução de problemas e à criatividade, porque a partir de uma tensão, proporcionariam uma reestruturação cognitiva.

Ainda referindo-se ao texto de Amatuzi, encontramos a referência de Tamminen sobre a complexidade do fenômeno religioso e de suas complicações: 1) o acesso que se pode ter à experiência religiosa é indireto, ou seja, se faz por meio do que as pessoas lembram e relatam, e em como elas a sentem e interpretam; 2) essa interpretação que os sujeitos fazem, depende de sua filosofia geral; e 3 ) a lembrança da experiência é determinada pelos valores presentes. Além disso, ele menciona também as cinco dimensões da religiosidade sistematizadas por Glock e Stark (conforme citados por Amatuzzi, 1998), que são dimensões que se interpenetram: dimensão experiencial (= experiência religiosa), dimensão ideológica (= crenças religiosas), dimensão intelectual (= conceitos com os quais é pensada), dimensão ritualística (= práticas religiosas) e dimensão conseqüente (= efeitos na vida diária).

$\mathrm{Na}$ análise da entrevista de Maria podem-se vislumbrar vários pontos de conexão com os autores anteriormente citados. Na perspectiva de Hay e de Jackson (conforme citados por Amatuzzi, 1998), contempla-se a experiência de Maria, com todas as suas manifestações somático-psicológicas, como uma capacidade e possibilidade intrínseca do ser humano, na qual, numa situação de aparente caos corporal e mental, o corpo-mente tem a capacidade de se adaptar de maneira criativa, valendo-se de seus mecanismos endógenos para voltar ao equilíbrio. Neste sentido, traçam-se paralelos com as experiências de emergência, perigos, doença, dificuldades, experiências de quase-morte ou de ameaça à existência do indivíduo (Grof, 2001; Lumby, 1998; Tamminen, citado por Amatuzzi, 1998).

Nestas experiências, o indivíduo pode ver sua própria morte com uma nitidez e realismo tão intensos que ele pode acreditar que está realmente morrendo (Grof, 2001; Lumby, 1998). Estas passagens são situadas no modelo de Grof (2001) no nível transpessoal, que são caracterizadas por elementos de criação e destruição do mundo, experiências filogenéticas, sequiências de morte e renascimento, cenas naturais (tempestades, nascer do sol etc), expansão da consciência e do ego, visões de seres celestiais e/ou infernais etc. Segundo Grof, estas experiências possuem um enorme potencial transformativo para o indivíduo, se são realizadas com a devida supervisão, preparação e cuidado, por parte tanto do indivíduo como da pessoa que orienta o processo.

De acordo com a hipótese de Lumby (1998), a eficácia destas experiências de quase-morte no tratamento de pessoas que fazem um uso problemático e abusivo de psicoativos estaria em sua capacidade de desencadear insights sistêmicos e orientações cognitivas explícitas características da consciência humana quando esta se encontra perante uma situação imediatamente ameaçadora à sua existência. Neste estado de consciência, a pessoa teria a oportunidade de vivenciar uma morte-simbólica, na qual seus valores, comportamentos e filosofia seriam questionados e, após a experiência, os insights poderiam ser vislumbrados e direcionados para uma nova prática cotidiana.

\begin{abstract}
...é como entrar numa nave, eu boto fé. Assim, você nunca viajou numa nave espacial, vamos imaginar aí... Aí tu entra numa nave de repente você se vê lá no espaço pff! Você sai de uma... você sai de um contexto assim ó, de coisas que você transformou pra você né, pra sua vida, coisas que você vai adquirindo ao longo dos anos né? Tipo, uma coisa material mesmo né, de tipo "isso é certo, isso é errado", "você tem que aprender isso porque se não você não vai ser ninguém na vida”. Sabe esses contextos assim e de repente, naquele momento que eu bebi o vegetal, eu percebi que a gente faz tanta coisa que é inútil pra nossa vida, e agente se mata por conta dessas coisas assim, e agente esquece de dar valor pras coisa que realmente são importantes. Eu acredito que é o nosso ser, o que é bom pra gente, que faz bem pra gente.
\end{abstract}

Aqui podemos dialogar com Tamminen (citado por Amatuzzi, 1998) e com Glock e Stark (citado por Amatuzzi, 1998). O acesso que tivemos da experiência de Maria possui a complicação de ser um relato de um evento passado, permeado por elaborações e interpretações feitas pela entrevistada. Tal complexidade pode ser comparada com as dimensões intelectual (conceitos) e ideológica (crenças), pois Maria teve tempo para lembrar, re-lembrar, conceituar e, inclusive, desenvolver uma linguagem religiosa que não possuía antes da experiência.

Entretanto, no nível das dimensões experiencial (experiência religiosa) e consequiente (efeitos na vida diária) o que importa é o significado e a compreensão que a experiência desencadeou em Maria. No caso, o sentido parece ter sido o de uma experiência de Deus, do numinoso, do raro, excepcional e extraordinário, a experiência esmagadora do mysterium tremendum et fascinas, de Sentido Radical, segundo Vaz (conforme citado Amatuzzi, 1998).

O vegetal abre tudo. Abre tudo, escancara mesmo. Escancara mesmo.

De maneira geral, podemos concluir que o abandono do uso problemático e abusivo de certos psicoativos por parte de Maria (cocaína e álcool) foi uma experiência radical, com efeitos de longo prazo em sua vida e que não parece possuir nenhuma característica de "troca de um psicoativo por outro" ou de dependência da instituição, embora Maria tenha passado por um processo de conversão religiosa.

Passou. Foi incrível. Incrível. Mudou assim, eu entrei no arco-íris, sabe quando você achou o pote de ouro no final do arco-íris? Foi isso que aconteceu na minha vida. Agora eu fico impressionada assim ó, e outra coisa, e essa história de largar de fumar, de largar essas coisa, eu vejo assim, o pessoal fala dessa história da tal da fisiologia, cara, a nossa cabeça é capaz de tanta coisa. As pessoas não sabem disso. (...) Eu não vejo o vegetal como uma necessidade. Tipo "é necessário pra minha sobrevivência”. Não. Eu vejo ele como um auxiliador pra minha consciência. Ele assim ó, quando eu conheci ele eu percebi que "puts, cara, que legal ele me ajudou a abrir várias coisas”, que tavam aqui cafifadas na minha cabeça e eu não sabia porque que tavam atrapalhando a minha vida, porque que eu tava seguindo determinados caminhos. É que nem aquelas gavetinhas da nossa memória, quando agente tem aula de psicologia, o pessoal fala que agente vai guardando 
até que agente não consegue mais abrir. (...) Aí, quando você vai bebendo constantemente ele, você vai aprendendo a abrir uma de cada vez. Entendeu?

Maria afirma nunca mais ter sentido vontade de consumir álcool ou cocaína - "Deus me livre, Nossa Senhora! Ninguém merece não" -, embora confessasse ainda sentir vontade de fumar tabaco (na época da pesquisa Maria estava há dois meses sem fumar).

Tudo isso ocorreu dentro de um processo, numa transformação que dialoga com os acontecimentos ao redor do indivíduo, não podendo ser reduzida nem a um aspecto estritamente farmacológico (possível efeito da ayahuasca per se) nem estritamente místico-religioso, conforme conclusão do estudo realizado por Grob e cols. (2004, p. 664-665):

Tal mudança foi particularmente notada na área de consumo excessivo de álcool, onde além dos cinco examinandos que tiveram diagnósticos anteriores do CIDI relativos a desordens por abuso de álcool, seis examinandos adicionais referiram padrões moderados de consumo de álcool que se aproximavam do status de diagnóstico psiquiátrico real na entrevista formal estruturada. Todos estes onze examinandos com envolvimento anterior com álcool alcançaram a completa abstinência pouco depois de se filiarem à seita da hoasca (nome da ayahuasca neste contexto). Além disto, foram bastante enfáticos quanto a transformações radicais no seu comportamento, atitudes em relação aos outros e visão da vida. Eles estão convictos de que têm sido capazes de eliminar sua raiva crônica, ressentimento, agressão e alienação, assim como em adquirir maior autocontrole, responsabilidade para com a família e comunidade e realização pessoal através da participação nas cerimônias da hoasca na UDV. Embora os efeitos salutares de um forte sistema de suporte em grupo e filiação religiosa não possam ser minimizados, não é inconcebível que o uso por longo tempo da hoasca por si mesmo possa ter tido um efeito terapêutico e positivo direto no status psiquiátrico e funcional dos indivíduos. Análises bioquímicas anteriores de preparados da hoasca indicaram significativa ação inibidora da monoamino-oxidase, $o$ que pode ser relevante para esses achados clínicos.

Para finalizar, com a palavra, Maria:

Porque hoje em dia eu dou muito mais valor na vida do que pessoas que nunca passaram por situações que eu passei.

\section{Referências}

Adaime, R. D. (no prelo). A pesquisa do inconsciente no século dos alucinógenos. Cadernos de Subjetividade.

Amatuzzi, M. M. (1998). A Experiência Religiosa: estudando depoimentos. Estudos de Psicologia, 15(2), 3-27.

Araújo, M. G. J. (2004). Cipó e Imaginário entre Seringueiros do Alto Juruá. Revista de Estudos da Religião 1, 41-59.

Araújo, W. S. (2004). A Barquinha: Espaço Simbólico de uma Cosmologia em Construção. Em B. C. Labate \& W. S. Araújo (Orgs.), O uso ritual da ayahuasca ( $2^{\mathrm{a}}$ ed., pp.541-555).
Campinas, São Paulo: Mercado de Letras.

Blewett, D. B. \& Chwelos, N. (2005). Handbookfor the Therapeutic Use of LSD-25: Individual and Group Procedures. Regina, Saskatchewan (Trabalho original publicado em 1959)

Brissac, S. (1999). Alcançar o Alto das Cordilheiras: A vivência mística de discípulos urbanos da União do Vegetal. Trabalho apresentado em IX Jornadas sobre Alternativas Religiosas na América Latina, Rio de Janeiro.

Brissac, S. (2004). José Gabriel da Costa: Trajetória de um brasileiro, Mestre e autor da União do Vegetal. Em B. C. Labate \& W. S. Araújo (Orgs.), O uso ritual da ayahuasca (2a ed., pp. 571-587). Campinas, São Paulo: Mercado de Letras.

Carneiro, H. (2005). A odisséia psiconáutica: a história de um século e meio de pesquisas sobre plantas e substâncias psicoativas. Em B. C. Labate \& S. L. Goulart (Orgs.), O uso ritual das plantas de poder (pp. 57-81). Campinas, São Paulo: Mercado de Letras.

Couto, F. L. (1989). Santos e Xamãs. Dissertação de Mestrado, Universidade de Brasília, Brasília.

Davis, W. (1997). One River: Explorations and Discoveries in the Amazon Rain Forest. New York: Simon \& Schuster Inc., Touchstone.

Dobkin de Rios, M. (1972). Visionary Vine: Hallucinogenic Healing in the Peruvian Amazon. Illinois: Waveland Press, Inc.

Fericgla, J. M. (1998). El peyote y la ayahuasca en las nuevas religiones mistéricas americanas. Em A. Espina (Ed.), Antropología en Castilla y León e Iberoamérica. Aspectos generales y religiosidades populares (pp. 325-347). Salamanca, España: Instituto de Investigaciones Antropológicas de Castilla y León.

Frecska, E., White, K. D. \& Luna, L. E. (2004). Effects of ayahuasca on binocular rivalry with dichoptic stimulus alternation. Psychopharmacology 173, 79-87.

Frenopoulo, C. (2004). The mechanics of religious synthesis in the Barquinha religion. Revista de Estudos da Religião 1, 19-40.

Furst, P. T. (1994). Alucinógenos y cultura. México: Fondo de Cultura Económica.

Goulart, S. (1996). As raízes culturais do Santo Daime. Dissertação de Mestrado, Universidade de São Paulo, São Paulo.

Grob, C. S. (2002). Hallucinogens: a reader. New York: Tarcher/ Putnam.

Grob, C. S., McKenna, D. J., Callaway, J. C., Brito, G. S., Neves, E. S., Oberlaender, G., Saide, O. L., Labigalini, E., Tacla, C., Miranda, C. T., Strassman, R. J., \& Boone, K. B. (2004). Farmacologia humana da hoasca: efeitos psicológicos. Em B. C. Labate \& W. S. Araújo (Orgs.), O uso ritual da ayahuasca $\left(2^{\mathrm{a}}\right.$ ed., pp. 653-669). Campinas, São Paulo: Mercado de Letras.

Grof, S. (2001). LSD psychoterapy ( $3^{\mathrm{a}}$ ed.) Sarasota, Florida: Multidisciplinary Association for Psychedelic Studies.

Groisman, A. (2000). Santo Daime in the Netherlands: An Anthropological Study of a New World Religion in a European Setting. Dissertação de Doutorado, Universidade de Londres, Londres.

Labate, B. C. (2003). Viagem ao encontro da iboga. Núcleo de Estudos Interdisciplinares sobre Psicoativos. Retirado em 21/08/2005, do NEIP (Núcleo de Estudos Interdisciplinares sobre Psicoativos), http://www.neip.info/downloads/Eboka. pdf.

Labate, B. C. (2004). A reinvenção do uso da ayahuasca nos centros urbanos. Campinas, São Paulo: Mercado de Letras.

Labate, B. C. \& Araújo, W. S. (Orgs.) (2004). O uso ritual da 
ayahuasca ( $2^{\mathrm{a}}$ ed.) Campinas, São Paulo: Mercado de Letras.

Labigalini, E. (1998). O uso de ayahuasca em um contexto religioso por ex-dependentes de álcool - um estudo qualitativo. Dissertação de Mestrado, Universidade Federal de São Paulo, São Paulo.

Leary, T., Metzner, R. \& Alpert, R. (1995). The Psychedelic Experience: a manual based on the Tibetan Book of the Dead. New York: Citadel Press. (Trabalho original publicado em 1964)

Lima, E. G. C. (2004). O uso ritual da Ayahuasca: da Floresta Amazônica aos centros urbanos. Monografia em Geografia Cultural, Universidade de Brasília, Brasília.

Lumby, M. (1998). Religions of the Twice-Born: Northwest Amazonian Ayahuasca Shamanism and Near-Death Experience. MAPS Newsletter 8(3), 16-17. Retirado em 21/08/2005, da MAPS (Multidisciplinary Association for Psychedelic Studies), http://www.maps.org/news-letters/v08n3/08316lum.htm.

Luna, L. E. (1986). Vegetalismo: shamanism among the mestizo population of the Peruvian Amazon. Studies in Comparative Religion, Almqvist and Wiksell International, Stockholm.

Mabit, J. (1996a). Takiwasi: Ayahuasca and Shamanism in Addiction Therapy. MAPS Newsletter 6(3). Retirado em 21/08/2005, da MAPS (Multidisciplinary Association for Psychedelic Studies), http://www.maps.org/news-letters/v06n3/06324aya.htm.

Mabit, J. (1996b). The Takiwasi Patient's Journey. MAPS Newsletter 6(3). Retirado em 21/08/2005, da MAPS (Multidisciplinary Association for Psychedelic Studies), http://www.maps.org news-letters/v06n3/06327tak.htm.

Mabit, J. (2002). Bleding Traditions - Using Indigenous Medicinal Knowledge to Treat Drug Addiction. MAPS Newsletter 12(2), 25-32. Retirado em 21/08/2005, da MAPS (Multidisciplinary Association for Psychedelic Studies), http://www.maps.org news-letters/v12n2/12225mab.htm.

Mabit, J. (2004). Produção visionária da ayahuasca no contexto dos curandeiros da Alta Amazônia Peruana. Em B. C. Labate \& W. S. Araújo (Orgs.), O uso ritual da ayahuasca (pp. 147-180). $2^{\text {a }}$ ed. Campinas, São Paulo: Mercado de Letras.

MacRae, E. (1992). Guiado pela Lua: Xamanismo e uso ritual da ayahuasca no culto do Santo Daime. São Paulo: Brasiliense.

McKenna, D. J., Callaway, J. C. \& Grob, C. S. (1998). The scientific investigation of Ayahuasca: a review of past and current research. The Heffter Review of Psychedelic Research 1, 6577. Retirado em 21/08/2005, do EROWID, http://www.erowid. org/chemicals/ayahuasca/ayahuasca_journal3.shtml.

McKenna, T. (1995). O retorno à Cultura Arcaica. Rio de Janeiro: Ed. Record

Ott, J. (1994). Ayahuasca Analogues: Pangaean Entheogens. Kennewick: Natural Books Co.

Samorini, G. (2002). Animals and Psychedelics: The Natural Word and the Instinct to Alter Consciousness. Rochester, Vermont: Park Street Prees.

Santos, R. G. (2004). A cura religiosa no contexto de um grupo da Barquinha: uma religião ayahuasqueira brasileira [Resumo]. Em Sociedade Brasileira de Etnobiologia e Etnoecologia (Org.), Resumos de comunicações científicas, V Simpósio Brasileiro de Etnobiologia e Etnoecologia. Mato Grosso: SBEE.

Schultes, R. E. \& Hofmann, A. (1992). Plants of the gods: their sacred, healing, and hallucinogenic powers. Rochester: Healing Arts Press.

Strassman, R. J. (1984). Adverse Reactions to Psychedelic Drugs: A Review of the Literature. The Journal of Nervous and Mental Disease, 172(10), 577-595.

Recebido em 15.12.2005

Primeira decisão editorial em 28.03.2006

Versão final em 21.09.2006

Aceito em 07.11.2006 